Article

\title{
Novel Polyketides Produced by the Endophytic Fungus Aspergillus Fumigatus from Cordyceps Sinensis
}

\author{
Da-Le Guo ${ }^{1}$, Xiao-Hua Li ${ }^{1}$, Dan Feng ${ }^{1}$, Meng-Ying Jin ${ }^{1}$, Yu-Mei Cao ${ }^{1}$, Zhi-Xing Cao ${ }^{1}$, \\ Yu-Cheng $\mathrm{Gu}^{2}$, Zhao Geng ${ }^{3}$, Fang Deng ${ }^{1, *}$ and Yun Deng ${ }^{1, *}$ \\ 1 The Ministry of Education Key Laboratory of Standardization of Chinese Herbal Medicine, State Key \\ Laboratory, Breeding Base of Systematic Research Development and Utilization of Chinese Medicine \\ Resources, School of Pharmacy, Chengdu University of Traditional Chinese Medicine, Chengdu 611137, \\ China; guodale@cdutcm.edu.cn (D.-L.G.); 18844144528@163.com (X.-H.L.); 18408210828@163.com (D.F.); \\ ivyweilan@163.com (M.-Y.J.); maycao12@163.com (Y.-M.C.); caozhixing007@163.com (Z.-X.C.) \\ 2 Syngenta Jealott's Hill International Research Centre, Berkshire RG42 6EY, UK; yucheng.gu@syngenta.com \\ 3 Sichuan Institute of Food and Drug Control, Chengdu 611731, China; gengzhao713@hotmail.com \\ * Correspondence: dengfang@cdutcm.edu.cn (F.D.); dengyun@cdutcm.edu.cn (Y.D.); \\ Tel.: +86-28-6180-0232 (Y.D.)
}

Received: 21 June 2018; Accepted: 7 July 2018; Published: 13 July 2018

\begin{abstract}
Five new polyketides, including two pairs of enantiomers and a racemate, were isolated from the fermentation broth of Aspergillus fumigatus, an endophytic fungus isolated from Cordyceps sinensis. Their structures were identified using one-dimensional (1D) and two-dimensional (2D) NMR experiments, and the absolute configurations of the enantiomers were confirmed using electronic circular dichroism (ECD) calculations. Compounds 1a and 2a exhibited inhibitory activity against the MV4-11 cell line in vitro, with $\mathrm{IC}_{50}$ values of $23.95 \mu \mathrm{M}$ and $32.70 \mu \mathrm{M}$, respectively.
\end{abstract}

Keywords: Aspergillus fumigatus; Cordyceps sinensis; isochromanes; chiral resolution; ECD calculation; cytotoxicity

\section{Introduction}

Aspergillus fumigatus (A. fumigatus) is an omnipresent saprophytic fungus normally residing in the soil or decaying organic matter [1], and it has the ability to produce secondary metabolites that meet its survival requirements under various environmental conditions [2]. Previous chemical investigations revealed the constituents to be terpenes [3,4], phenolics [5], diketopiperazine [6], and other nitrogen compounds $[7,8]$, which exhibit a variety of biological activities. For instance, fumagillin, which is a typical secondary metabolite from A. fumigatus, has the capacity to inhibit angiogenesis in tumor cells [9].

With the purpose of searching compounds with novel structures and bio-activities from endophytes of traditional Chinese medicine (TCM), A. fumigatus, as an endophytic fungus of Cordyceps sinensis, was chosen, and three new isochromanes were isolated from its fermentation broth (Figure 1). These polyketides were presumed to be the mixtures of enantiomers due to their approximate-to-zero optical rotation. Chiral resolution was further applied to two of these racemates, and it yielded two pairs of enantiomers. The absolute configurations of these enantiomers were further verified using quantum-chemical electronic circular dichroism (ECD) calculations. Details of the isolation, structure identification, and cytotoxicity evaluation of these new compounds are reported herein. 


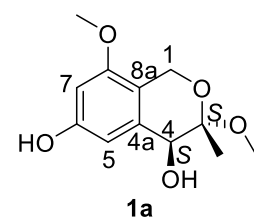

$1 \mathbf{a}$<smiles>COc1cc(O)cc2c1OCC2(C)O</smiles>

$2 a^{\text {Ō }}$<smiles>COc1cc(O)cc2c1OC[C@]2(C)OC</smiles>

1b<smiles>COc1cc(O)cc2c1OCO2</smiles>

$2 b$<smiles>COc1cc2c(cc1OC)CC(C)(OC)OC2</smiles>

3

Figure 1. The structures of compounds obtained from Aspergillus fumigatus.

\section{Results and Discussion}

Compound $\mathbf{1}$ (Figure 1) was obtained as a yellow gum. The molecular formula of $\mathbf{1}$ was established using HRESIMS as $\mathrm{C}_{12} \mathrm{H}_{16} \mathrm{O}_{5}$ (found 263.0897, calculated for [M+Na] ${ }^{+}$263.0890). The infrared (IR) spectrum showed intense absorption bands of hydroxy at $v_{\max } 3397.5 \mathrm{~cm}^{-1}(\mathrm{OH})$, and $1613.2 \mathrm{~cm}^{-1}$ and $1371.6 \mathrm{~cm}^{-1}$ (phenyl), as well as a methylene band at $2932.1 \mathrm{~cm}^{-1}$. The ${ }^{1} \mathrm{H}$ NMR spectrum displayed two aromatic proton signals at $\delta 6.38(1 \mathrm{H}, \mathrm{d}, J=2.2 \mathrm{~Hz}, \mathrm{H}-5)$ and $6.33(1 \mathrm{H}, \mathrm{d}, J=2.2$ $\mathrm{Hz}, \mathrm{H}-7)$, two methoxyl signals at $\delta 3.76(3 \mathrm{H}, \mathrm{s}, 8-\mathrm{OMe})$ and $3.30(3 \mathrm{H}, \mathrm{s}, 3-\mathrm{OMe})$, one oxymethylene signal at $\delta 4.46(1 \mathrm{H}, \mathrm{d}, J=15.3 \mathrm{~Hz}, \mathrm{H}-1)$ and $4.41(1 \mathrm{H}, \mathrm{d}, J=15.3 \mathrm{~Hz}, \mathrm{H}-1)$, and one methine signal at $\delta 4.00(1 \mathrm{H}, \mathrm{s}, \mathrm{H}-4)$ and $1.46(3 \mathrm{H}, \mathrm{s}, 3-\mathrm{Me})$. The ${ }^{13} \mathrm{C}$ NMR and DEPT spectra of Compound 1 exhibited 12 carbon signals, including six aromatic carbons at $\delta 158.4$ (C-8), 157.2 (C-6), 137.3 (C-4a), 114.2 (C-8a), 109.0 (C-5), and 99.0 (C-7), a quaternary carbon at $\delta 101.5$ (C-3), one methine carbon at $\delta 70.4$ (C-4), one methylene carbon at $\delta 60.7$ (C-1), two methoxyl carbons at $\delta 55.8$ (8-OMe) and 49.8 (3-OMe), and a methyl signal at $\delta 19.1$ (C-3). The HMBC correlations of H-1/C-8 and C-3, H-5/C-4, 3-Me/C-3 and C-4, 3-OMe/C-3, and 8-OMe/C-8, as well as the NOESY correlations of H-7/8-OMe confirmed the presence of an isochromane scaffold, and the primary structure of $\mathbf{1}$ was established as 3,8-dimethoxy-3-methylisochromane-4,6-diol (Figure 2). The NOESY correlations of H-4/3-OMe indicated that the relative configuration of $\mathbf{1}$ should be $3 R^{*}, 4 R^{*}$ (Figure 3). Compound $\mathbf{1}$ was presumed to be a mixture of enantiomers, as its optical rotation was approximate to zero. Further chiral HPLC analysis confirmed the presence of a pair of anticipated enantiomers. Subsequent chiral resolution was applied, and two enantiomers, $\mathbf{1 a}$ and $\mathbf{1} \mathbf{b}$, were obtained successfully. The ECD experiment and ECD calculation of 1 were conducted to determine its absolute configuration. The calculated ECD spectra of 3S, 4S-1 fitted the experimental spectrum of 1a nicely, while the calculated ECD spectra of 3R, 4R-1 matched the experimental spectra of $\mathbf{1} \mathbf{b}$ quite well, allowing the absolute configurations of $\mathbf{1 a}$ and $\mathbf{1 b}$ to be determined as $3 \mathrm{~S}, 4 \mathrm{~S}$ and $3 \mathrm{R}, 4 \mathrm{R}$, respectively.

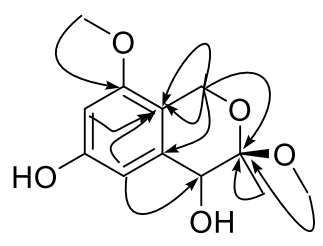

1 and 2

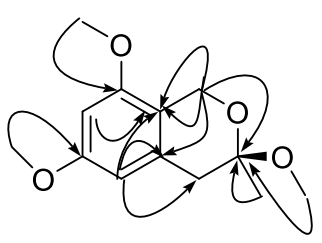

3

Figure 2. Key HMBC correlations of Compounds 1-3. 
Compound 2 (Figure 1) was obtained as a yellow gum. It was assigned the same molecular formula, $\mathrm{C}_{12} \mathrm{H}_{16} \mathrm{O}_{5}$, as $\mathbf{1}$ on the basis of HRESIMS. The NMR spectra of 2 were similar to those of 1, which indicated that it was an epimer of $\mathbf{1}$. Both the changes in chemical shift of $\mathrm{H}-4(\delta 4.36)$, C-4 ( $\delta 72.6)$, and C-3 ( $\delta 99.5)$, and the absence of NOESY correlation of H-4/3-OMe indicated its relative configuration should be $3 \mathrm{R}^{*}, 4 \mathrm{~S}^{*}$. Based on its optical rotation, chiral separation was applied, and it successfully produced a pair of enantiomers. The ECD experiment and ECD calculation of $\mathbf{2 b}$ were conducted to determine its absolute configuration. The results (Figure 4 ) indicated that the calculated ECD curve of 3R, 4S-2 was similar to the experimental ECD spectrum of (+)-2 (2b), which designated the configuration of (+)-2 as 3R, 4S-3,8-dimethoxy-3-methylisochromane-4,6-diol. On the other hand, (-)-2 was assigned to be 3S, 4R-3,8-dimethoxy-3-methylisochromane-4,6-diol (2a) accordingly.

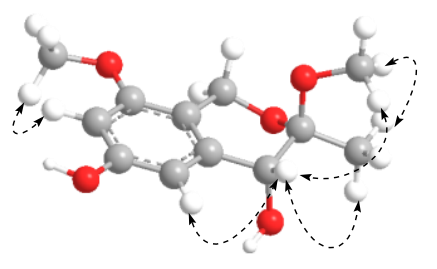

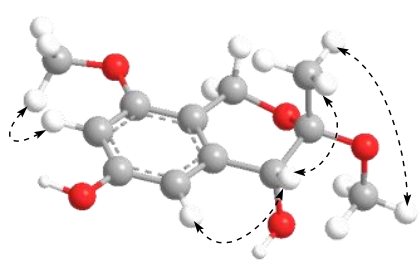

2

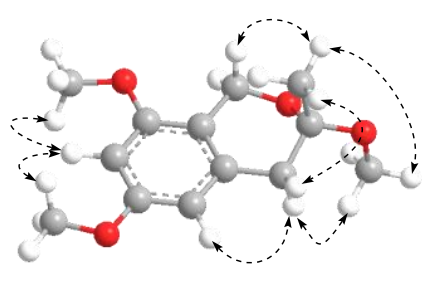

3

Figure 3. The key NOESY correlations of Compounds 1-3.

Compound 3 (Figure 1) was isolated as a yellow gum. Its molecular formula was established as $\mathrm{C}_{13} \mathrm{H}_{18} \mathrm{O}_{4}$ on the basis of the HRESIMS through the pseudo-molecular ion peak at $m / z 261.1107$ $[\mathrm{M}+\mathrm{Na}]^{+}$(calculated for 261.1097). The ${ }^{1} \mathrm{H}$ and ${ }^{13} \mathrm{C}$ NMR spectra indicated that 3 possessed a similar structure to 1 and 2 except for a methylene $\left(\delta_{\mathrm{H}}: 2.85, \mathrm{~d}, J=16.4 \mathrm{~Hz}, 2.73, \mathrm{~d}, J=16.4 \mathrm{~Hz} ; \delta_{\mathrm{C}}\right.$ : 39.8) instead of a methine group at C-4, and the presence of another methoxyl $\left(\delta_{\mathrm{H}}: 3.78 ; \delta_{\mathrm{C}}: 55.7\right)$. The HMBC correlation of 6-Me/C-6 readily located this methoxyl at C-6. Thus, 3 was elucidated to be 3,6,8-trimethoxy-3-methylisochromane.
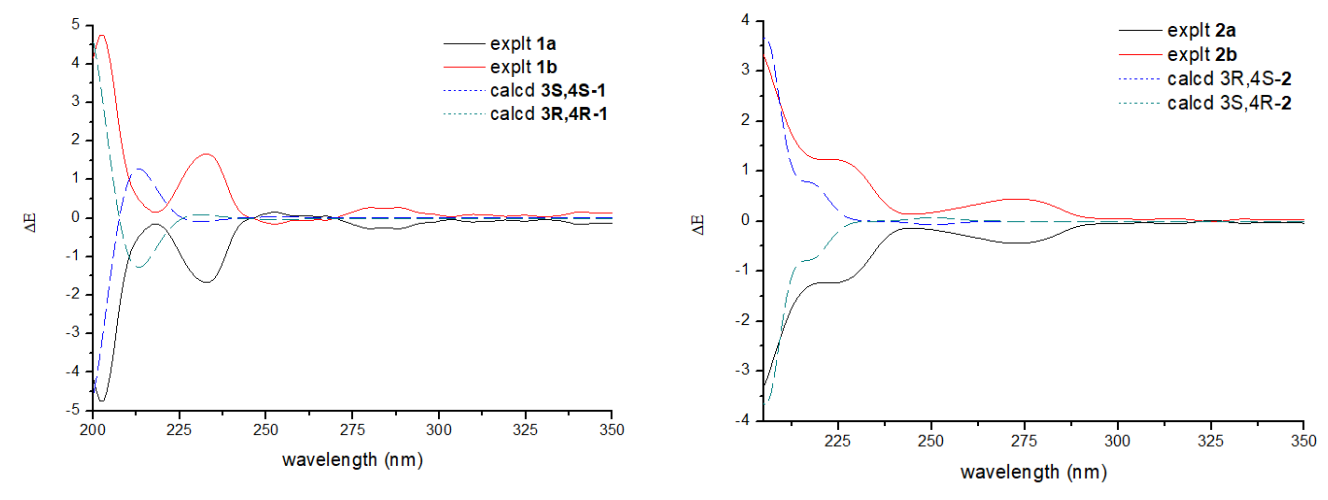

Figure 4. Experimental electronic circular dichroism (ECD) spectra of Compounds 1 and 2 and their calculated curves.

The MTT method was applied to evaluate the cytotoxicity of these compounds against MDA-ME-231 and MV4-11 cancer cell lines. Compounds 1a and 2a showed moderate growth inhibition against the MV4-11 cell line with $\mathrm{IC}_{50}$ values of $23.95 \mu \mathrm{M}$ and $32.70 \mu \mathrm{M}$, respectively.

\section{Materials and Methods}

\subsection{General Experimental Procedures}

The UV spectra were measured on a PerkinElmer Lambda 35 UV-VIS spectrophotometer (PerkinElmer, Waltham, MA, USA). The IR spectra were recorded on a PerkinElmer Spectrum One 
Fourier-transform IR (FT-IR) spectrometer, (PerkinElmer, Waltham, MA, USA). The ECD spectra were obtained on a JASCO (Oklahoma City, OK, USA) J-810 spectrometer. The optical rotations were measured on a JASCO (Oklahoma City, OK, USA) P-1020 polarimeter. The NMR spectra were recorded on a Bruker (Billerica, MA, USA) 400 spectrometer, for one-dimensional (1D) and two-dimensional (2D) NMR. The HRESIMS data were recorded on a Bruker (Billerica, MA, USA) Micro TOF-Q II mass spectrometer. Preparative HPLC was performed on a Hanbon Sci. \& Tech. (Huaian, Jiangsu, China) NP7000 serials instrument equipped with a Hanbon Sci. \& Tech. (Huaian, Jiangsu, China) NU3000 serials UV detector, using a Kromasil 100-5- $\mathrm{C}_{18}$ column $(10 \times 250 \mathrm{~mm}, 5 \mu \mathrm{m}$; Akzo Nobel Pulp and Performance Chemicals AB, Bohus, Sweden) for normal separation, and a column Chiralpak IC column $(4.6 \times 250 \mathrm{~mm}, 5 \mu \mathrm{m}$; Chiral Technologies, West Chester, PA, USA) for chiral resolution. Column chromatography (CC) was performed on a silica gel (200-300 mesh; Qingdao Marine Chemical Inc., Qingdao, China) and a Sephadex LH-20 (GE-Healthcare Bio-Sciences AB, Uppsala, Sweden). All solvents used were of analytical grade.

\subsection{Fungal Material}

The A. fumigatus strain was separated from Cordyceps sinensis collected in Xiahe county, China in May 2017. The fungus was identified using morphological observation and sequence (GenBank acccession No. MG519287) analyses of the ITS region of recombinant DNA (rDNA). The identified strain was inoculated into 24,500 mL Erlenmeyer flasks, each containing $200 \mathrm{~mL}$ of potato dextrose agar (PDA) at room temperature, agitated on an orbital shaker at $200 \mathrm{rpm}$ for seven days to produce the seed culture. The fermentation was carried out in one hundred and twenty $1000 \mathrm{~mL}$ Fernbach flasks, each containing $10 \mathrm{~mL}$ of seed culture and $400 \mathrm{~mL}$ of medium (soluble starch $0.8 \%$, peptone $0.5 \%$, $\mathrm{NaCl} 0.2 \%, \mathrm{CaCO}_{3} 0.2 \%, \mathrm{MgSO}_{4} \cdot 7 \mathrm{H}_{2} \mathrm{O} 0.05 \%$, and $\mathrm{K}_{2} \mathrm{HPO}_{4} 0.05 \%$ ), and was incubated at $25^{\circ} \mathrm{C}$ on a rotary shaker at $200 \mathrm{rpm}$ for 15 days.

\subsection{Fractionation and Isolation}

The culture was filtered to separate the mycelia and the broth. The broth was firstly extracted with petroleum ether, followed by ethyl acetate. The ethyl acetate solution was concentrated to a brown residue $(9.3 \mathrm{~g})$. The crude extract was fractionated using liquid chromatography on a silica gel $(6 \times 30 \mathrm{~cm})$ with a gradient elution of $\mathrm{CHCl}_{3} / \mathrm{MeOH}$. The fractions eluted with a ratio of 75:25 were combined, $(1.08 \mathrm{~g})$ and were further subjected to Sephadex LH-20 column chromatography $(4 \times 180 \mathrm{~cm}$; mobile phase $\left.\mathrm{CHCl}_{3} / \mathrm{MeOH}, 1: 1\right)$, which afforded three sub-fractions (Fr.1-Fr.3). Fr.3 (91 mg) was purified using a preparative HPLC with a reversed-phase column (5u $100 \mathrm{~A} ; 10 \times 250 \mathrm{~mm}$; mobile phase $\left.\mathrm{MeOH} / \mathrm{H}_{2} \mathrm{O}, 65: 35\right)$ to furnish Compounds 1 (3.0 mg), 2 (1.9 mg), and 3 (2.9 mg). Compound 1 was further separated using HPLC with a Chiralpak IC column (mobile phase n-hexane/isopropanol, 85:15) to yield Compounds $\mathbf{1 a}\left(0.33 \mathrm{mg}, \mathrm{R}_{\mathrm{t}} 10.4 \mathrm{~min}\right)$ and $\mathbf{1 b}\left(0.42 \mathrm{mg}, \mathrm{R}_{\mathrm{t}} 20.6 \mathrm{~min}\right)$, while Compound $\mathbf{2}$ was further separated under the same conditions to give Compounds $\mathbf{2 a}\left(0.16 \mathrm{mg}, R_{t} 8.1 \mathrm{~min}\right)$ and $\mathbf{2 b}$ (0.26 mg, $\left.\mathrm{R}_{\mathrm{t}} 28.5 \mathrm{~min}\right)$.

\subsubsection{R,4S-3,8-Dimethoxy-3-methylisochromane-4,6-diol (1a)}

Yellow gum, $[\alpha]_{\mathrm{D}}^{20}=+167.9(\mathrm{c}=0.02, \mathrm{MeOH})$, IR $(\mathrm{KBr}): 3397.5,2932.1,1613.2,1371.6,1055.3 \mathrm{~cm}^{-1}$; $\lambda_{\max } 207.3$ (3.74), 281.5 (2.72); ${ }^{1} \mathrm{H}\left(\mathrm{CD}_{3} \mathrm{OD}, 400 \mathrm{MHz}\right)$ and ${ }^{13} \mathrm{C}$ NMR $\left(\mathrm{CD}_{3} \mathrm{OD}, 100 \mathrm{MHz}\right)$ spectroscopic data (see Table 1 and Supplementary Material); HRESIMS $m / z 263.0897\left[\mathrm{M}+\mathrm{Na}^{+}\right.$(calculated for $^{-}$ $\mathrm{C}_{12} \mathrm{H}_{16} \mathrm{O}_{5} \mathrm{Na}^{+}$, 263.0890). 
Table 1. The ${ }^{1} \mathrm{H}(400 \mathrm{MHz})$ and ${ }^{13} \mathrm{C}(100 \mathrm{MHz}) \mathrm{NMR}$ data ( $\delta$ in ppm, multiple $J$ in $\left.\mathrm{Hz}\right)$ of Compounds 1-3.

\begin{tabular}{|c|c|c|c|c|c|c|}
\hline \multirow{2}{*}{ Position } & \multicolumn{2}{|l|}{$1^{a}$} & \multicolumn{2}{|l|}{2} & \multicolumn{2}{|l|}{3} \\
\hline & $\delta_{\mathrm{H}}$ & $\delta_{\mathrm{C}}$ & $\delta_{\mathbf{H}}$ & $\delta_{\mathrm{C}}$ & $\delta_{\mathrm{H}}$ & $\delta_{\mathrm{C}}$ \\
\hline 1 & $\begin{array}{c}4.41, \mathrm{~d}, 15.3 \\
\mathrm{~Hz} \\
4.46, \mathrm{~d}, 15.3 \\
\mathrm{~Hz}\end{array}$ & 60.7 & $\begin{array}{l}4.56, \mathrm{~d}, 15.2 \mathrm{~Hz} \\
4.43, \mathrm{~d}, 15.2 \mathrm{~Hz}\end{array}$ & 60.6 & $\begin{array}{l}4.65, \mathrm{~d}, 15.1 \mathrm{~Hz} \\
4.44, \mathrm{~d}, 15.1 \mathrm{~Hz}\end{array}$ & 60.2 \\
\hline 2 & - & - & - & - & - & - \\
\hline 3 & - & 101.5 & - & 99.5 & - & 98.8 \\
\hline 4 & $4.00, \mathrm{~s}$ & 70.4 & $4.36, \mathrm{~s}$ & 72.6 & $\begin{array}{l}2.85, \mathrm{~d}, 16.4 \mathrm{~Hz} \\
2.73, \mathrm{~d}, 16.4 \mathrm{~Hz}\end{array}$ & 39.8 \\
\hline $4 a$ & - & 137.3 & - & 138.6 & - & 134.4 \\
\hline 5 & $6.38, \mathrm{~d}, 2.2 \mathrm{~Hz}$ & 109.0 & $6.63, \mathrm{~d}, 2.1 \mathrm{~Hz}$ & 105.5 & $6.33, \mathrm{~d}, 2.1 \mathrm{~Hz}$ & 105.5 \\
\hline 6 & - & 157.2 & - & 158.5 & - & 161.0 \\
\hline 7 & $6.33, \mathrm{~d}, 2.2 \mathrm{~Hz}$ & 99.0 & $6.28, \mathrm{~d}, 2.1 \mathrm{~Hz}$ & 97.9 & $6.33 \mathrm{~d}, 2.1 \mathrm{~Hz}$ & 96.9 \\
\hline 8 & - & 158.4 & - & 156.8 & - & 157.4 \\
\hline $8 a$ & - & 114.2 & - & 114.6 & - & 115.2 \\
\hline 3-Me & $1.46, \mathrm{~s}$ & 19.1 & $1.49, \mathrm{~s}$ & 20.5 & $1.44, \mathrm{~s}$ & 23.4 \\
\hline 3-OMe & $3.30, \mathrm{~s}$ & 49.8 & $3.31, \mathrm{~s}$ & 49.1 & $3.28, \mathrm{~s}$ & 48.8 \\
\hline 6-OMe & - & - & - & - & 3.78 & 55.7 \\
\hline 8-OMe & $3.76, \mathrm{~s}$ & 55.8 & $3.75, \mathrm{~s}$ & 55.8 & 3.72 & 55.8 \\
\hline
\end{tabular}

\subsubsection{R,4R-3,8-Dimethoxy-3-methylisochromane-4,6-diol (1b)}

Yellow gum, $[\alpha]_{\mathrm{D}}^{20}=-167.9(\mathrm{c}=0.01, \mathrm{MeOH})$, spectrometric (UV, IR, NMR, MS, and HRESIMS) data are the same as those of $\mathbf{1 a}$.

\subsubsection{S,4R-3,8-Dimethoxy-3-methylisochromane-4,6-diol (2a)}

Yellow gum, $[\alpha]_{\mathrm{D}}^{20}=-260.1(\mathrm{c}=0.01, \mathrm{MeOH}), \mathrm{IR}(\mathrm{KBr}): 3421.1,2940.8,1623.6,1384.6,1061.2 \mathrm{~cm}^{-1}$; $\lambda_{\max } 211.1$ (3.76), $282.2(2.73) ;{ }^{1} \mathrm{H}\left(\mathrm{CD}_{3} \mathrm{OD}, 400 \mathrm{MHz}\right)$ and ${ }^{13} \mathrm{C}$ NMR $\left(\mathrm{CD}_{3} \mathrm{OD}, 100 \mathrm{MHz}\right)$ spectroscopic data (see Table 1); HRESIMS $m / z 263.0893[\mathrm{M}+\mathrm{Na}]^{+}$(calculated for $\mathrm{C}_{12} \mathrm{H}_{15} \mathrm{O}_{5} \mathrm{Na}^{+}$, 263.0890).

\subsubsection{R,4S-3,8-Dimethoxy-3-methylisochromane-4,6-diol (2b)}

Yellow gum, $[\alpha]_{\mathrm{D}}^{20}=+260.1(\mathrm{c}=0.01, \mathrm{MeOH})$, spectrometric (UV, IR, NMR, MS, and HRESIMS) data are the same as those of $\mathbf{2 a}$.

\subsubsection{3,6,8-Trimethoxy-3-methylisochromane (3)}

Yellow gum, $[\alpha]_{\mathrm{D}}^{20}=+0.9(\mathrm{c}=0.11, \mathrm{MeOH}), \mathrm{IR}(\mathrm{KBr}): 3435.5,2923.0,1638.5,1384.2,1074.7 \mathrm{~cm}^{-1}$; $\lambda_{\max } 210.6$ (3.85), 281.0 (2.97); ${ }^{1} \mathrm{H}\left(\mathrm{CD}_{3} \mathrm{OD}, 400 \mathrm{MHz}\right)$ and ${ }^{13} \mathrm{C}$ NMR $\left(\mathrm{CD}_{3} \mathrm{OD}, 100 \mathrm{MHz}\right)$ spectroscopic data (see Table 1); HRESIMS $m / z 261.1107$ [M + Na] ${ }^{+}$(calculated for $\mathrm{C}_{12} \mathrm{H}_{16} \mathrm{O}_{4} \mathrm{Na}^{+}$, 261.1097).

\subsection{MTT Assay}

The MV4-11 and MDA-ME-231 cells (American Type Culture Collection, Manassas, VA, USA) were grown in DMEM or IMDM medium containing $10 \% \mathrm{FBS}$ in $5 \% \mathrm{CO}_{2}$ at $37{ }^{\circ} \mathrm{C}$. When the cells entered the exponential growth phase, they were seeded in a 96-well plate and incubated overnight. Afterward, media containing various concentrations of tested compounds from $3.125 \mu \mathrm{M}$ to $100 \mu \mathrm{M}$ were added to each well. Additionally, 0.1\% DMSO was used as a blank control, while taxol was used as a positive control. After the incubation period $\left(72 \mathrm{~h}\right.$ at $\left.37^{\circ} \mathrm{C}\right), 20 \mu \mathrm{L} /$ well of MTT reagent $(5 \mathrm{mg} / \mathrm{mL})$ was added, and the wells were incubated for $2-4 \mathrm{~h}$, before $50 \mu \mathrm{L} /$ well of 20 acidified SDS was added to lyse the cells. Finally, the absorbance was measured at $570 \mathrm{~nm}$ to evaluate the inhibition effects of the tested compounds on cell growth. All experiments were performed in triplicate. 


\section{Conclusions}

Among the five new compounds obtained from a TCM-related strain A. fumigatus, two pairs of novel enantiomers were discovered. The MTT method was used to detect the cytotoxicity of these compounds against MDA-ME-231 and MV4-11 cells. Compounds 1a and 2a exhibited moderate cytotoxic activity against the MV4-11 cell line with $\mathrm{IC}_{50}$ values of $23.95 \mu \mathrm{M}$ and $32.70 \mu \mathrm{M}$, respectively.

Supplementary Materials: The following are available online, Pages 1-3: The computational details; Figures S1-S2: HPLC chromatograms of 1 and 2 using a Chiralpak IC column; Figures S3-S23: MS and NMR spectra of Compounds 1-3.

Author Contributions: D.-L.G. and Y.D. conceived and designed the experiments; X.-H.L., M.-Y.J. and Y.-M.C., performed the experiments; D.-L.G., Z.-X.C., and Z.G. analyzed the data; D.F. contributed materials; Y.-C.G. and F.D. wrote the paper.

Funding: This work was financially supported by grants from the National Natural Sciences Foundation of China (81373961); Sichuan Provincial Youth Science and Technology Innovation Team (2016TD0006, 2015TD0028); Project Funded by China Postdoctoral Science Foundation (2017M622985); and Project Funded by Department of Education in Sichuan Province (18ZA0191).

Acknowledgments: The authors wish to thank Jing Yang (KIB CAS, China) for the help in ECD calculation.

Conflicts of Interest: No potential conflict of interest was reported by the authors.

\section{References}

1. Haas, H. Fungal siderophore metabolism with a focus on Aspergillus fumigatus. Nat. Prod. Rep. 2014, 31, 1266-1276. [CrossRef] [PubMed]

2. Kwon-Chung, K.J.; Sugui, J.A. Aspergillus fumigatus-What makes the species a ubiquitous human fungal pathogen? PLoS Pathog. 2013, 9, e1003743. [CrossRef] [PubMed]

3. Chu, M.; Mierzwa, R.; He, L.; Xu, L.; Patel, M.; Patel, D.; Chan, T.M. Structure of Sch 528647: A new antitumor antibiotic related to Fumagillin. J. Antibiot. 2001, 54, 1096-1099. [CrossRef] [PubMed]

4. Wang, Y.; Li, D.H.; Li, Z.L.; Sun, Y.J.; Hua, H.M.; Liu, T.; Bai, J. Terpenoids from the Marine-Derived Fungus Aspergillus fumigatus YK-7. Molecules 2016, 21, 31. [CrossRef] [PubMed]

5. Cutler, H.G.; Lauren, D.R.; Wilkins, A.L.; Holland, P.T.; Hill, R.A.; Dugan, F.M. Ruakuric acid: A natural product from Aspergillus fumigatus. Phytochemistry 1996, 43, 209-214. [CrossRef]

6. Wang, F.Z.; Fang, Y.C.; Zhu, T.J.; Zhang, M.; Lin, A.Q.; Gu, Q.Q.; Zhu, W.M. Seven new prenylated indole diketopiperazine alkaloids from holothurian-derived fungus Aspergillus fumigatus. Tetrahedron 2008, 64, 7986-7991. [CrossRef]

7. Magotra, A.; Kumar, M.; Kushwaha, M.; Awaschi, P.; Raina, C.; Gupta, A.P.; Shah, B.A.; Gandhi, S.G.; Chaubey, A. Epigenetic modifier induced enhancement of fumiquinazoline C production in Aspergillus fumigatus (GA-L7): An endophytic fungus from Grewia asiatica L. ABM Express 2017, 7, 43. [CrossRef] [PubMed]

8. Shi, Y.S.; Zhang, Y.; Chen, X.Z.; Zhang, N.; Liu, Y.B. Metabolites produced by the endophytic fungus Aspergillus fumigatus from the stem of Erythrophloeum fordii oliv. Molecules 2015, 20, 10793-10799. [CrossRef] [PubMed]

9. Sin, N.; Meng, L.H.; Wang, M.Q.W.; Wen, J.J.; Bornmann, W.G.; Crews, C.M. The anti-angiogenic agent fumagillin covalently binds and inhibits the methionine aminopeptidase, MetAP-2. Proc. Natl. Acad. Sci. USA 1997, 94, 6099-6103. [CrossRef] [PubMed]

Sample Availability: Samples of the compounds $\mathbf{1 a}, \mathbf{1 b}$, and $\mathbf{3}$ are available from the authors.

(C) 2018 by the authors. Licensee MDPI, Basel, Switzerland. This article is an open access article distributed under the terms and conditions of the Creative Commons Attribution (CC BY) license (http://creativecommons.org/licenses/by/4.0/). 